\section{Síndrome de Parsonage-Turner: Reporte de tres casos, revisión de la literatura y propuesta de algoritmo diagnóstico}

\section{Resumen}

Presentamos una serie de tres casos de Síndrome de Parsonage-Turner valorados a lo largo de los dos últimos años. Todos los pacientes se presentaron por primera vez como un dolor de hombro irradiado a trapecio y la parte proximal del brazo asociado a disminución de la sensibilidad de la extremidad afectada. En todos se observó el signo de la escápula alada. Incluimos una revisión de la literatura y proponemos un algoritmo simplificado de diagnóstico de este síndrome.
Carlos Guillen Astete ${ }^{1,2}$, Mónica Luque Alarcón ${ }^{3}$, Cristina de la Casa

Resino ${ }^{2}$ Joaquin Carreño Glaria²

1 Servicio de Reumatología - Hospital Universitario Ramón y Cajal

2 Servicio de Urgenicas - Hospital Universitario Ramón y Cajal

3 Servicio de Neurología - Hospital El Tajo

\section{Correspondencia:}

Dr. Carlos Guillen

” cguillen.hrc@salud.madrid.org

\title{
Abstract
}

We present a series of three cases of Parsonage-Turner disease presented over the last two years. All patients presented by the first time a unilateral acute shoulder girdle pain radiated to the trapezius ridge and upper arm associated to weakness and sensitive impairment of the affected limb. All of them presented the scapular winging sign. We have performed a review of literature and proposed a simplified algorithm to consider the diagnosis of this syndrome.

\section{Introducción}

La primera descripción de un síndrome caracterizado por dolor de hombro agudo no dependiente de los movimientos asociado con distintos grados de debilidad y alteraciones de la sensibilidad de la extremidad comprometida, se hizo en 1897 [1-3]. En 1948, se acuñó el término de síndrome de Parsonage-Turner (SPT) a este cuadro clínico conocido también como neuralgia amiotrófica o plexopatía braquial idiopática [4]. 
Tabla 1. Resumen de la evolución de los casos descritos.

\begin{tabular}{|c|c|c|c|c|}
\hline Caso & $\begin{array}{l}\text { Tratamiento } \\
\text { farmacológico }\end{array}$ & $\begin{array}{l}\text { Tratamiento no } \\
\text { farmacológico }\end{array}$ & Resolución & Observaciones \\
\hline 1 & $\begin{array}{l}\text { Tramadol 150mg/d; } \\
\text { Celecoxib 200mg/d; } \\
\text { Gabapentina } 600 \mathrm{mg} / \mathrm{d} \text {. }\end{array}$ & TENS & $\begin{array}{l}\text { Resolución completa } \\
\text { después de } 12 \text { semanas. }\end{array}$ & $\begin{array}{l}\text { Se inició TENS } 4 \text { semanas después } \\
\text { del diagnóstico. }\end{array}$ \\
\hline 2 & $\begin{array}{l}\text { Oxicodona/Naloxona 40/20 } \\
\text { mg/d; Naproxeno } 500 \text { mg/ } \\
\text { bid; Pregabalina } 150 \text { mg/d. }\end{array}$ & $\begin{array}{l}\text { TENS, ejercicios } \\
\text { de estiramiento. }\end{array}$ & $\begin{array}{l}\text { Resolución completa } \\
\text { después de } 16 \text { meses. }\end{array}$ & $\begin{array}{l}\text { Los ejercicios se iniciaron dos meses } \\
\text { después del diagnóstico. }\end{array}$ \\
\hline 3 & $\begin{array}{l}\text { Prednisona } 15 \mathrm{mg} / \mathrm{d} \text {; } \\
\text { Tramadol } 150 \text { mg/d; } \\
\text { Pregabalina } 150 \text { mg/d. }\end{array}$ & $\begin{array}{l}\text { TENS, ejercicios } \\
\text { de estiramiento. }\end{array}$ & $\begin{array}{l}\text { El dolor desapareció } \\
\text { a los } 6 \text { meses. Se } \\
\text { recuperó el } 80 \% \text { de } \\
\text { la fuerza muscular } \\
\text { después de un año. }\end{array}$ & $\begin{array}{l}\text { Se aplicó una escalada descendente de } \\
\text { prednisona después de dos meses de } \\
\text { tratamiento, hasta } 5 \mathrm{mg} / \mathrm{d} \text {. Los ejercicios } \\
\text { se iniciaron } 3 \text { meses después del } \\
\text { diagnóstico. }\end{array}$ \\
\hline
\end{tabular}

Presentamos tres casos consecutivos de SPT valorados entre 2011 y 2014 en tres instituciones distintas. Las presentaciones clínicas se describen separadamente. En la tabla 1 se resume la evolución de los casos.

\section{Casos clínicos}

Caso 1. Un varón de 40 años se presentó en urgencias con una historia de 7 días de evolución caracterizada por dolor agudo de hombro con patrón intermitente. El dolor se había incrementado en los últimos 3 días y se había asociado a debilidad proximal del miembro superior un día antes de consultar por urgencias. Al examen físico se observó que el dolor era independiente a los movimientos activos o pasivos. Pese a que se había registrado una ligera debilidad de los músculos flexores del brazo, el paciente fue dado de alta con tratamiento antiinflamatorio y dos días después volvió a urgencias. En esta nueva ocasión el paciente presentaba debilidad en músculos extensores y flexores del hombro y el dolor era constante. El dolor se irradiaba al trapecio y al brazo y el signo de la escápula alada era positivo. Una tomografía computarizada (TC) de columna cervical fue realizada e informada como normal. Se solicitó una ecografía musculoesquelética del hombro que fue informada como normal, y finalmente una resonancia magnética nuclear (RMN) excluyó compromiso radicular cervical. Tras un interrogatorio profundo, el paciente reconoció haber sufrido una infección viral de vías respiratorias altas dos semanas antes.

Caso 2. Una mujer de 45 años desarrolló una historia de 2 semanas de evolución de dolor de hombro tras un traumatismo sobre el tercio inferior del brazo izquierdo. De acuerdo con ella, la intensidad del traumatismo no justificaba el dolor actual que, por otro lado, describía como permanente pero especialmente intenso en las noches. En la exploración física se observaba discreta debilidad muscular en territorio supraescapular y el signo de la escápula alada positivo. Los movimientos pasivos del hombro no desencadenaban dolor. Se solicitó un estudio ecográfico del hombro que fue informada como normal. Previamente, dos meses antes del episodio, el paciente fue sometido a un estudio cervical por RM debido a dolor esporádico en el cuello. Este estu- 
dio no mostró radiculopatía alguna. Una semana después del inicio de los síntomas un EMG reveló alteraciones parcheadas de la conducción a nivel del nervio supraescapular.

Caso 3. Un varón de 22 años se presentó en el SU debido a parálisis del miembro superior derecho asociado con dolor disruptivo de gran intensidad. Su padre había presentado un cuadro similar a los 25 años de edad que resolvió de forma espontánea. El paciente había sido vacunado contra el tétanos diez días antes del inicio de los síntomas en el hombro izquierdo. Inicialmente el paciente describió dolor difuso alrededor del hombro y brazo. La parálisis se inició el mismo día de la visita a urgencias. Al examen físico presentaba debilidad 1/5 proximal y $2 / 5$ distal y el signo de la escápula alada era evidente. La radiografía y ecografía de hombro fueron normales. Un EMG realizado al día siguiente demostró compromiso de todo el plexo braquial. Durante el ingreso se realizó una RM de columna cervical que excluyó compromiso compresivo de las raíces nerviosas.

\section{Discusión}

EI SPT es una condición rara caracterizada por el desarrollo de dolor intenso, constante o esporádico a nivel del hombro (habitualmente unilateral), irradiado al trapecio, al tercio superior y medio del brazo y eventualmente a todo el miembro superior [3-5]. El dolor se asocia casi siempre a distintos grados de debilidad regional que pueden comprometer músculos extensores, flexores, rotadores o incluso todos los grupos musculares del hombro y del brazo y habitualmente se describe como constante aunque los pacientes suelen percibirlo con mayor intensidad por las mañanas al despertar $[3,4,6]$. La duración de los síntomas es variable, habiéndose descrito casos de 2 semanas a varios meses de duración [4,7-9]. En el examen físico, es crucial de- mostrar integridad del manguito rotador mediante la exploración pasiva y activa. El signo de la escápula alada (separación del borde escapular interno mientras el paciente en bipedestación se inclina apoyando los brazos contra una superficie vertical) es muy específico de la alteración de la conducción del nervio supraescapular $[4,11]$. Es frecuente que los pacientes presenten parestesias a nivel del tercio medio y distal del brazo. En la mayoría de los casos la afectación del SPT es unilateral sin embargo se han reportado casos de afectación clínicamente unilateral con hallazgos electromiográficos bilaterales [11].

La etiología del SPT no es completamente conocida sin embargo se han identificado factores de riesgo y eventos desencadenantes hasta en un $80 \%$ de los pacientes [11]. Entre los eventos mayormente descritos en los reportes de casos se encuentran la cirugía cervical [12,13], infecciones virales [12], traumatismo reciente o pasado, inmunizaciones (tétanos, rubéola, pertussis, difteria, gripe aviar) $[12,14]$, desensibilizaciones alérgicas [15], ejercicio extenuante y administración de contrastes radiológicos [11]. Procesos reumatológicos autoinmunes como enfermedades del tejido conectivo, lupus eritematoso difuso, arteritis de células gigantes, poliarteritis nudosa también se asocian con SPT [16-18]. Esta asociación y la relación con infecciones virales así como otras condiciones relacionadas con procesos inmunes sugieren que el SPT podría estar producido por una alteración vasculítica transitoria autoinmune no bien conocida a fecha de hoy [12].

La incidencia de SPT es de alrededor de 1.6 casos por cada 100000 pacientes/año [3,11,12]. Debido a su difícil diagnóstico esta cifra podría estar infraestimada. Muchos casos son diagnosticados erróneamente de tendinosis del manguito rotador o patología compresiva de raíces nerviosas cervicales, y se tratan con antiinflamatorios no esteroideos (AINEs) u opioides $[3,8,11,13]$. 


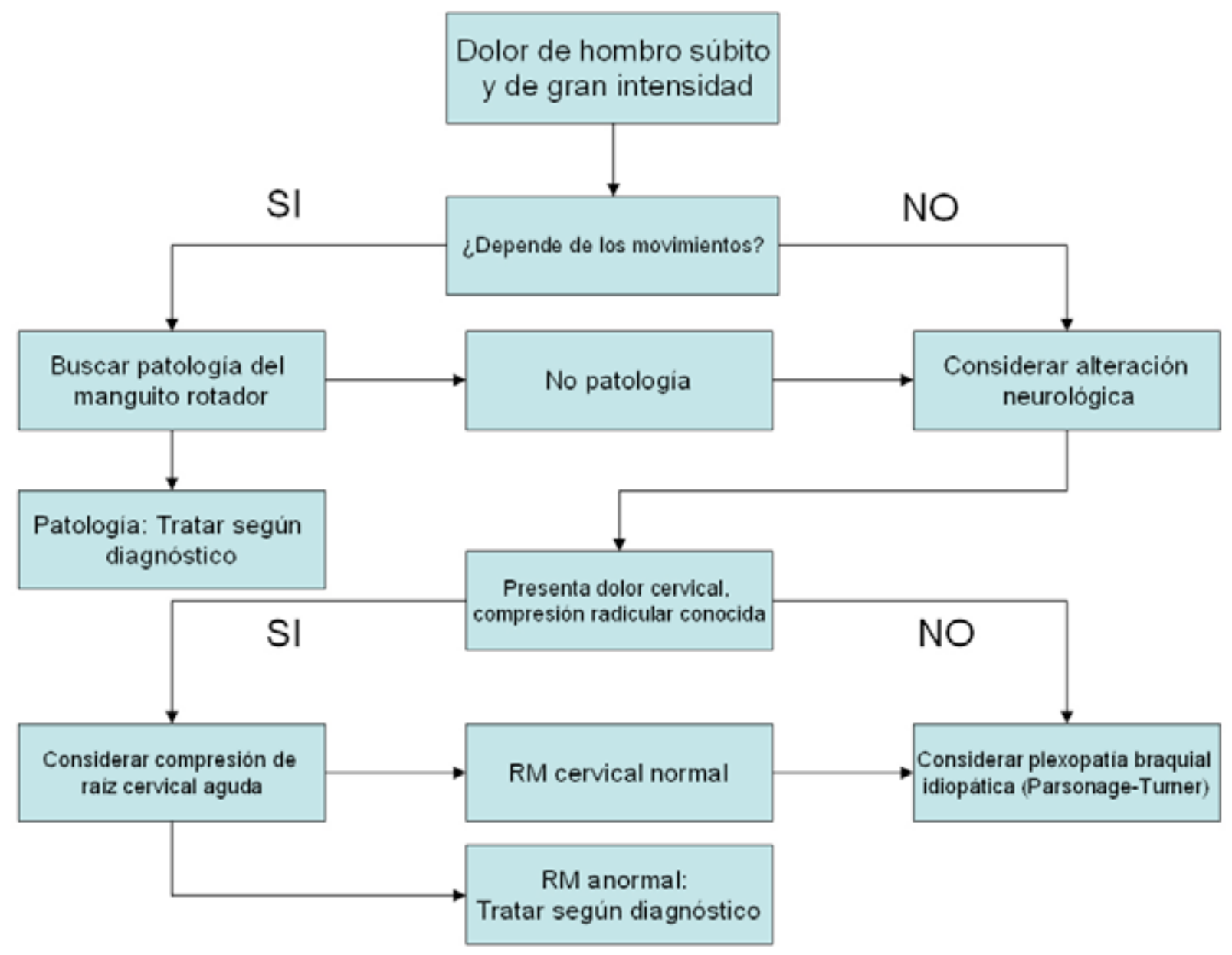

Figura 1. Propuesta de algoritmo diagnóstico para el diagnóstico de SPT.

\section{Propuesta de algoritmo diagnóstico} (Fig. 1)

Un cuadro clínico compatible con SPT puede ser la forma de presentación de varios procesos compresivos de las raíces nerviosas que constituyen el plexo braquial sin embargo, por definición la demostración de estos procesos excluyen el diagnóstico.

La mayor proporción de patologías del manguito rotador se presentan como dolor agudo o subagudo de dolor de hombro con un patrón mecánico bien descrito por los pacientes. Una exploración física en la que se demuestre tendinopatía del hombro excluye el diagnóstico. Un problema diag- nóstico mayor surge cuando la debilidad y el dolor aparecen de forma simultánea. Puede ser difícil valorar un dolor de hombro no relacionado a los movimientos si el paciente tiene compromiso de la fuerza. Debido a ello, es útil realizar una ecografía musculoesquelética del hombro. Un dolor de hombro cuya intensidad y limitación funcional no puede ser explicada por los hallazgos ecográficos es un buen candidato para el diagnóstico de SPT.

La segunda consideración que debe hacerse en estos pacientes es el de la posibilidad de compresión de una raíz nerviosa. La distrofia muscular no es una forma común de presentación del SPT. Esto se puede utilizar con el propósito de descartar las radicu- 
lopatías, especialmente en pacientes con procesos compresivos cervicales conocidos. En ausencia de distrofia muscular es importante constatar el buen estado de las raíces nerviosas cervicales por medio de las maniobras de elongación de plexos y verificando el estado de los reflejos osteotendinosos. Si bien en el SPT la sintomatología no se corresponde con la semiología de la compresión radicular, las maniobras de elongación de plexos pueden desencadenar el dolor. En estos casos, la presentación irruptiva del dolor de hombro es la clave para el diagnóstico diferencial.

El diagnóstico de SPT no requiere la demostración de un EMG anormal. De hecho, durante los primeros días del inicio de los síntomas el EMG puede ser normal o inespecífico [11]. La presencia de debilidad es un buen predictor de anormalidades electromiográficas a partir de la segunda o tercera semana desde establecida la sospecha de SPT. El patrón electromiográfico es casi siempre de denervación pero su presentación es parcheada $[19,20]$. Debido a ello es extremadamente importante que la solicitud del estudio electromiográfico indique la sospecha de este síndrome.

El SPT tiene un buen pronóstico en términos generales. En las primeras semanas, se puede con- seguir alivio del dolor con AINEs, opioides menores, dosis bajas de esteroides o drogas neurolépticas [5,11,21-23]. La estimulación nerviosa eléctrica transcutánea (TENS, por sus siglas en inglés) ha sido probada exitosamente como tratamiento adyuvante en esta fase [11]. En situaciones en las que existe debilidad muscular al tiempo que alteraciones de la sensibilidad, el tratamiento farmacológico debe asociarse a otras medidas: El uso de TENS puede ser útil para restaurar la fuerza una vez resuelto el dolor y los ejercicios de estiramiento deben indicarse de acuerdo al nivel de debilidad muscular y a la condición física basal de paciente. En pacientes con denervación completa, los ejercicios deben ser diferidos y progresivamente incluidos en la rutina fisioterápica.

No existen recomendaciones generales sobre el uso de AINEs en el manejo del SPT. El uso de prednisona parece disminuir el tiempo hasta la recuperación pero las dosis o la escalada descendente no se han identificado claramente [24]. Por otro lado, el uso de drogas antivirales debe considerarse cuando se sospecha de infecciones virales como agentes causales, especialmente cuando la sospecha es de infección por virus del herpes $[10,25,26]$. 


\section{Referencias}

1. Allen I. The neurological complication of serum treatment. Lancet. 1931;2:1128-31.

2. Dyke $S$. Peripheral nerve lesions after anti-tetanic serum. Lancet. 1918;1:570.

3. Turner J. Acute brachial radiculitis. Br Med J. 1944;2:992-4.

4. Parsonage, MJ, y JW Turner. Neuralgic amyotrophy: The shoulder-girdle syndrome. Lancet (1948);1:973-78.

5. Magee KR, Dejong RN. Paralytic brachial neuritis. Discussion of clinical features with review of 23 cases. JAMA J Am Med Assoc. 1960;174:1258-62.

6. Dineen J, Saidha S, McNamara B, Plant B, Ryan AM. Brachial neuritis masquerading as acute coronary syndrome. Ir J Med Sci. 2011;180(1):291-4.

7. Subramony SH. AAEE case report \#14: neuralgic amyotrophy (acute brachial neuropathy). Muscle Nerve. 1988;11(1):39-44.

8. Schott GD. A chronic and painless form of idiopathic brachial plexus neuropathy. J Neurol Neurosurg Psychiatry. 1983;46(6):555-7

9. Weinstein EA. Localized nontraumatic neuropathy in military personnel. Arch Neurol Psychiatry. 1947;57(3):369-76.

10. Feinberg JH, Doward DA, Gonsalves A. Cervical radiculopathy vs Parsonage-Turner syndrome: a case report. HSS J Musculoskelet J Hosp Spec Surg. 2007;3(1):106-11.

11. Feinberg JH, Radecki J. Parsonage-turner syndrome. HSS J Musculoskelet J Hosp Spec Surg. 2010;6(2):199-205.

12. Fibuch EE, Mertz J, Geller B. Postoperative onset of idiopathic brachial neuritis. Anesthesiology. 1996;84(2):455-8.

13. Malamut RI, Marques W, England JD, Sumner AJ. Postsurgical idiopathic brachial neuritis. Muscle Nerve. 1994;17(3):320-4.

14. Weintraub MI, Chia DT. Paralytic brachial neuritis after swine flu vaccination. Arch Neurol. 1977;34(8):518.

15. Wong $\mathrm{L}$, Dellon AL. Brachial neuritis presenting as anterior interosseous nerve compression--implications for diagnosis and treatment: a case report. J Hand Surg. 1997;22(3):536-9.

16. Bloch SL, Jarrett MP, Swerdlow M, Grayzel Al. Brachial plexus neuropathy as the initial presentation of systemic lupus erythematosus. Neurology. 1979; 29(12): 1633-4.

17.Allan SG, Towla HM, Smith CC, Downie AW, Clark JC. Painful brachial plexopathy: an unusual presentation of polyarteritis nodosa. Postgrad Med J. 1982;58(679):311-3.

18. Cordero Sánchez M, Calvo Arenillas Jl, Gutierrez DA, Gutierrez Alonso JL, de Portugal Alvarez J. Cervical radiculopathy: a rare symptom of giant cell arteritis. Arthritis Rheum. 1983;26(2):207-9.

19. Weikers NJ, Mattson RH. Acute paralytic brachial neuritis. A clinical and electrodiagnostic study. Neurology. 1969;19(12):1153-8.

20. Martin WA, Kraft GH. Shoulder girdle neuritis: a clinical and electrophysiological evaluation. Mil Med. 1974;139(1):21-5.

21. Jing-Chun Z, Chun-Jing X, Jia-Ao Y. Parsonage-Turner Syndrome in Second-Degree Contact Burns. J Burn Care Res Off Publ Am Burn Assoc. 2014;
22. Smith DPW, Elliott JA, Helzberg JH. Intravenous corticosteroid therapy for bilateral parsonage-turner syndrome: a case report and review of the literature. Reg Anesth Pain Med. 2014;39(3):243-7.

23. Smith CC, Bevelaqua A-C. Challenging pain syndromes: Parsonage-Turner syndrome. Phys Med Rehabil Clin N Am. 2014;25(2):265-77.

24. Van Alfen N, van Engelen BGM, Hughes RAC. Treatment for idiopathic and hereditary neuralgic amyotrophy (brachial neuritis). Cochrane Database Syst Rev. 2009;(3):CD006976.

25. Crooks RJ, Jones DA, Fiddian AP. Zoster-associated chronic pain: an overview of clinical trials with acyclovir. Scand J Infect Dis Suppl. 1991;80:62-8.

26. Dubinsky RM, Kabbani $H$, El-Chami Z, Boutwell C, Ali $H$, Quality Standards Subcommittee of the American Academy of Neurology. Practice parameter: treatment of postherpetic neuralgia: an evidence-based report of the Quality Standards Subcommittee of the American Academy of Neurology. Neurology. 2004;63(6):959-65.

\section{Opina sobre este artículo:}

\section{(f) 8 in $8+5$. $t$}

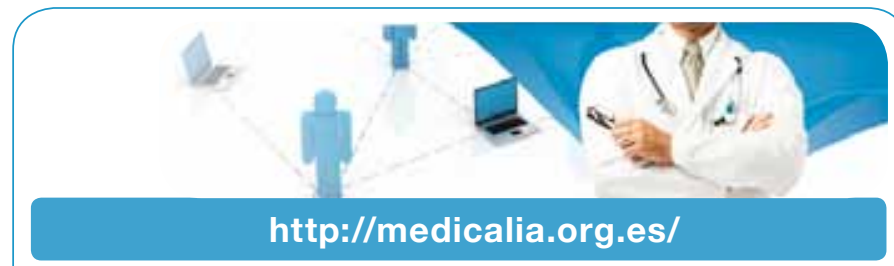

Los médicos disponen de una red social para intercambiar experiencias clínicas, comentar casos y compartir conocimiento. También proporciona acceso gratuíto a numerosas publicaciones. ¡Únase ahora!

\section{Publish with iMedPub}

http://www.imed.pub

Acta Reumatológica es una revista que tiene por fin la difusión de estudios clínicos relacionados con aspectos prácticos del diagnóstico, tratamiento y seguimiento de pacientes con patología reumatológica, de estudios epidemiológicos relacionados con patología inflamatoria y musculoesquelética de presentación común o infrecuente en la práctica clínica tanto en población adulta como pediátrica, de casos clínicos de patología poco habitual o de presentaciones inhabituales de patología frecuente, de imágenes didácticas e ilustrativas en reumatología y del estado actual e innovación en la formación especializada en reumatología. 